\title{
Latitudinal gradient in response of wing polymorphism to photoperiod in a flightless bug, Pyrrhocoris apterus (Heteroptera: Pyrrhocoridae)
}

\author{
RADOMÍR SOCHA \\ Institute of Entomology, Academy of Sciences, Branišovská 31, CZ-370 05 České Budějovice, Czech Republic; \\ e-mail: socha@entu.cas.cz
}

Key words. Wing dimorphism, macroptery, photoperiodic response, geographical variation, firebug, Pyrrhocoris apterus

\begin{abstract}
The aim of this study was to determine if there is a latitudinal gradient in the photoperiodic regulation of wing dimorphism in the flightless bug, Pyrrhocoris apterus (L.). For this purpose individuals from three geographical populations (Israel, Spain and Czech Republic) were reared under different photoperiods and the wing length of the adults analyzed. The highest percentage of long-winged (macropterous) specimens was found in the population from Israel (35.3\%), whereas percentages of macroptery were lower in the cultures from Spain (9.5\%) and Czech Republic (8.6\%). A higher proportion of macropterous specimens was recorded in the northern population of $P$. apterus kept under long daylengths (Czech Republic, $16 \mathrm{~h}$ ) than in the southern populations (Spain, $14-15 \mathrm{~h}$; Israel, $12 \mathrm{~h}$ ). The results indicate that there is a latitudinal gradient in the critical photoperiod determining wing length in $P$. apterus.
\end{abstract}

\section{INTRODUCTION}

Photoperiodic determination of wing length is one of the most important adaptations to a seasonally changing environment and commonly occurs in insects, particularly in temperate zones (Vepsäläinen, 1971; Masaki, 1973; Beck, 1980; Tauber et al., 1986; Harada \& Numata, 1993). In numerous wing-polymorphic species wing length is usually associated with other key life history traits such as fecundity, age at first reproduction, flight potential and diapause (Dingle, 1981, 1996; Roff, 1986; Danks, 1987), and is often geographically dependent (Iwanaga et al., 1987; Mousseau \& Roff, 1989; Shimizu \& Masaki, 1993; Imasheva et al., 1994). However, there is no data on the geographical variations in photoperiodic regulation of wing length for the important experimental model insect, Pyrrhocoris apterus (L.) (Socha, 1993).

The firebug, $P$. apterus, is a common Palaearctic species, which is mainly distributed in the Mediterranean area and eastern and central Asia (Socha, 1993). It is a dimorphic heteropteran, producing short-winged (brachypterous) adults and a non-flying long-winged (macropterous) morph (Honěk, 1976). Honěk (1987) found no obvious differences in the proportion of macropters among the $F_{1}$ offspring of some Mediterranean and central Asian populations of the bug, when he reared them under a long-day $(18 \mathrm{~L}: 6 \mathrm{D})$ photoperiod at $26^{\circ} \mathrm{C}$. However, his experiments are unrealistic, because such a daylength does not naturally occur at the localities from which the Mediterranean populations originated, and the wing length of the bug might be photoperiodically and geographically dependent. The aim of this study was to test the hypothesis that $P$. apterus is characterized by a latitudinal gradient in wing polymorphism, and that the latitudinal gradient in the critical photoperiod regulating macroptery in this bug involves a long-day photoperiodic response in northern populations and a short-day photoperiodic response in southern populations.

\section{MATERIALS AND METHODS}

Stocks of $P$. apterus were reared on an ad libitum supply of linden seeds and water at a constant temperature of $26^{\circ} \mathrm{C}$. One temperate and two Mediterranean cultures of this bug were used in this study. The temperate culture originated from bugs collected at České Budějovice (Czech Republic, $49 \mathrm{~N}^{\circ}$ ). The Mediterranean cultures were established from bugs collected at $\mathrm{La}$ Fosca-Palamós (Spain, $42 \mathrm{~N}^{\circ}$ ), and at Ma'agal Michael (Israel, $33 \mathrm{~N}^{\circ}$ ). The $\mathrm{F}_{1}$ offspring of the cultures were maintained at $26^{\circ} \mathrm{C}$ either under the photoperiodic regimes 18L : 6D (Czech Republic culture) or $16 \mathrm{~L}: 8 \mathrm{D}$ (Spain and Israel cultures), which allowed continuous breeding. Larvae and adults were kept in 0.5 liter jars (approximately 40 specimens per jar), and food and water were replenished twice a week.

Animals used for determining the percentages of brachypterous and macropterous individuals and for the analysis of the wing-form response to photoperiod were reared from egg to adult under a particular photoperiod at $26^{\circ} \mathrm{C}$. For this purpose eggs were collected daily from each culture, and transferred to different photoperiods (photophase in the range 0-24 h). Newly ecdysed adult males and females (200-800 specimens reared at each photoperiod) were scored as either brachypterous or macropterous. The response to photoperiod was expressed as a curve: the percentage of macropterous individuals plotted against photoperiod. To give an overall picture of the statistical reliability of the results the $95 \%$ confidence limits (the lower and the upper confidence limits of percentages) were estimated according to Zar (1996).

\section{RESULTS}

The $P$. apterus from all three geographical origins differed in both percentage of macroptery and in their response to photoperiod (Fig. 1). The population from Israel had the highest percentage of macropters $(35.1 \%)$, 

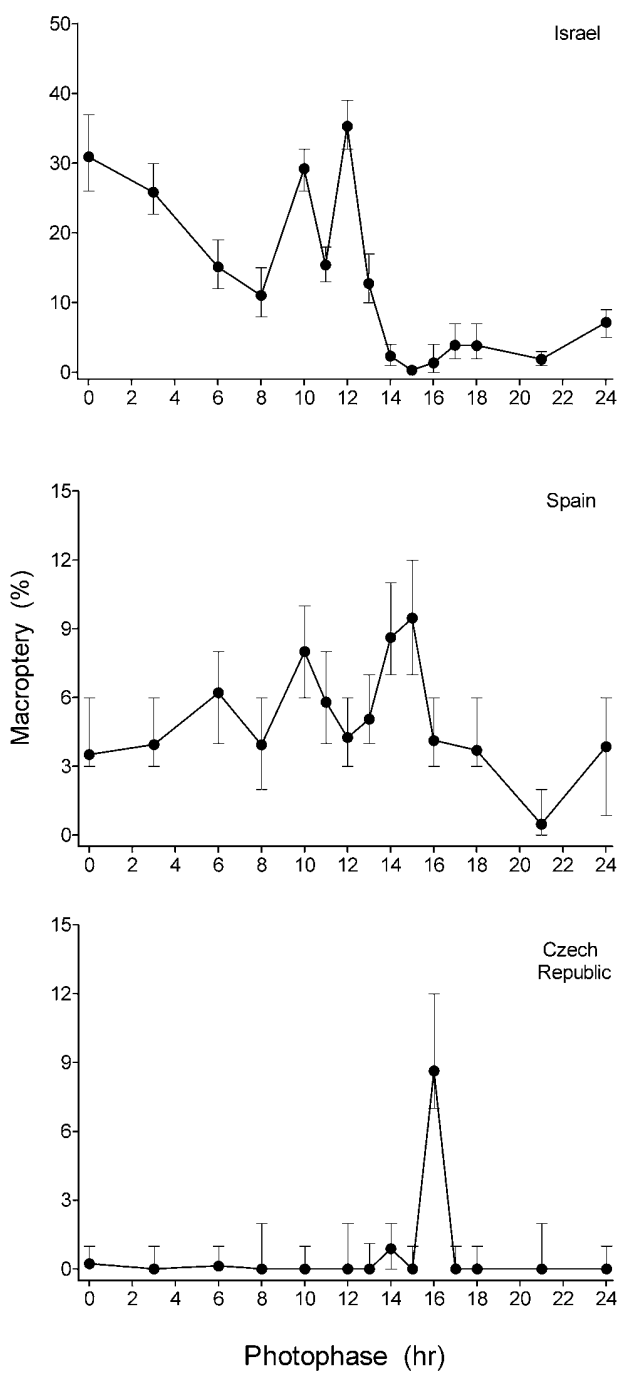

Fig. 1. The percentage of macropterous individuals produced in response to photoperiods from $0-24 \mathrm{~h}$ by three geographical separated populations of $P$. apterus. Error bars indicate 95\% confidence limits (cf. Zar, 1996).

that from Spain the next lowest $(9.47 \%)$ and that from Czech Republic the lowest (8.6\%). Maximum levels of macroptery were reached at longer daylengths in the northern population (Czech Republic, $16 \mathrm{~h}$ ) than the southern population (Spain, 14-15 h; Israel, $12 \mathrm{~h}$ ). No significant differences between the proportions of macropterous males and females were observed. The population from Israel produced the highest proportion of macropterous specimens (35.3\%) under short-day (12L : 12D) conditions, while the culture from the Czech Republic produced only brachypterous individuals when reared under this photoperiodic regime. In contrast, the highest percentage of macropterous individuals in the Czech culture (8.64\%) was produced under long day (16 h) conditions, whereas the percentage of macropterous specimens produced by the Israel culture was almost the lowest $(1.36 \%)$ when reared under this photoperiod. The other main difference is that the bugs from the Czech
Republic respond to a narrower photoperiodic range than those from Israel and Spain. Unlike the Czech culture, specimens from Israel and Spain produced a high proportion of macropterous individuals when kept in continuous darkness.

\section{DISCUSSION}

The results demonstrated a north to south gradient in the photoperiodic response regulating wing polymorphism in P. apterus. The critical daylength inducing the macropterous morph was considerably shorter for bugs from Israel than for those from Spain and the Czech Republic when reared at constant temperature of $26^{\circ} \mathrm{C}$. The photoperiodic response curves for the bugs indicates that the induction of the macropterous morph involves a long-day photoperiodic response (with a critical photoperiod of about $16.5 \mathrm{~h}$ ) for those from Czech Republic and a short-day photoperiodic response (with a critical photoperiod of about $12.5 \mathrm{~h}$ ) for those from Mediterranean (Israel). Thus, P. apterus is an insect in which there is a clear effect of photoperiod on wing dimorphism and in which a latitudinal variation in the photoperiodic response has been demonstrated (Vepsäläinen, 1978; Tauber et al., 1986). There is strong positive correlation of wing length and wing area with latitude in both wild Drosophila melanogaster and their laboratory-raised descendants (Land et al., 1999). In addition to the different percentages of macropterous individuals in the different populations, the shapes of the photoperiodic response curves for $P$. apterus from different areas differ. Populations from Israel and Spain have one shape and that from the Czech Republic another. It is possible that the differences in longitude of Spain and Israel might account for similarities in the shape of the curves for those two populations even though the percentages of macroptery differ. To answer this question further experimental data for one or two additional populations of this bug is needed.

In contrast to $P$. apterus, a closely related species, $P$. sibiricus, produces the highest proportion of macropterous individuals when reared under a short-day ( $12 \mathrm{~L}$ : 12D) photoperiod (Sakashita et al., 1995). The major difference in the environmental control of wing length in these phylogenetically related species is thought to be the critical photoperiods. However, this is unlikely, as they compared data for populations collected from different latitudes ( $P$. sibiricus from Okayama, Japan, $\sim 35^{\circ} \mathrm{N}$; Sakashita et al., 1995; P. apterus from central Bohemia, Czech Republic, $\sim 50^{\circ} \mathrm{N}$; Honěk, 1976). It is probable that different results would be obtained, if a similar comparative study were done using bugs collected from similar latitudes. This assumption is supported by a comparison of the data obtained in this study for the Israel $\left(33^{\circ} \mathrm{N}\right)$ population of $P$. apterus and that for P. sibiricus from similar latitudes (Sakashita et al., 1995), which showed no important differences in the photoperiodic responses regulating wing length pattern in these pyrrhocorids.

In natural populations of $P$. apterus in central Europe there are usually $1-5 \%$ macropterous specimens (Honěk, 1987). The penetrance of the macropterous allele depends 
not only on photoperiod, but also on temperature and population density (Honěk, 1976). Selection for macroptery decreases sensitivity, but does not alter the critical photoperiod (Honěk, 1979). Photoperiodic reaction is modified by temperature: the optimum for macropter production is $25-27^{\circ} \mathrm{C}$ while lower $\left(21^{\circ} \mathrm{C}\right)$ and higher $\left(31-33^{\circ} \mathrm{C}\right)$ temperatures decrease the incidence of macropters (Honěk, 1981). The proportion of macropters in temperate populations of $P$. apterus usually increases in June to August, so that during the warm season of the year it may sometimes exceed $60 \%$ in some local temperate populations (Honěk, 1981). As in P. apterus, macropters of some other heteropterans, e.g. Microvelia douglasi, also occur in natural populations most frequently from late June to early July, when many habitats become unstable and dry out (Muraji et al., 1989). Despite the inhibitory effect of lower and higher temperatures on the production of macropterous specimens in $P$. apterus (Honěk, 1979, 1981), geographical differences in the way temperature modifies the wing-morph response to photoperiod in this bug cannot be excluded and will be the topic of a further detailed study.

ACKNOWLEDGEMENTS. This study was supported by grant No 206/99/0068 from the Grant Agency of Czech Republic. Author thanks to T. Pavlíček and P. Stary for the supply of $P$. apterus populations from Israel and Spain, and D. Rienesslová for technical assistance.

\section{REFERENCES}

Beck S.D. 1980: Insect Photoperiodism, 2nd edn. Academic Press, New York, 288 pp.

DANKS H.V. 1987: Insect Dormancy: An Ecological Perspective. Biological Survey of Canada Monograph No. 1, Natl. Mus. Nat. Sci., Ottawa, 439 pp.

Dingle H. 1981: Geographic variation and behavioural flexibility in milkweed bug life histories. In Denno R.F. \& Dingle H. (eds): Insect Life History Patterns: Habitat and Geographic Variation. Springer-Verlag, Berlin, Heidelberg, New York, pp. 57-73

Dingle H. 1996: Migration. The Biology of Life on the Move. Oxford University Press, New York, $474 \mathrm{pp}$.

Harada T. \& Numata H. 1993: Two critical day lengths for the determination of wing forms and the induction of adult diapause in the water strider, Aquarius paludum. Naturwissenschaften 80: 430-432.

HoNĚK A. 1976: Factors influencing the wing polymorphism in Pyrrhocoris apterus (Heteroptera, Pyrrhocoridae). Zool. Jb. Syst. 103: 1-22.

HONĚK A. 1979: Independent response of 2 characters to selection for insensitivity to photoperiod in Pyrrhocoris apterus. Experientia 35: 762-763.
HonĚK A. 1981: Temperate and wing polymorphism in natural populations of Pyrrhocoris apterus L. (Heteroptera, Pyrrhocoridae). Zool. Jb. Syst. 108: 487-501.

HONĚK A. 1987: Wing polymorphism in Pyrrhocoris apterus (Heteroptera, Pyrrhocoridae): penetrance of recessive macropterous homozygotes and duration of larval development. Genetica 73: 211-215.

Imasheva A.G., Bubli O.A. \& Lazebny O.E. 1994: Variation in wing length in Eurasian natural populations of Drosophila melanogaster. Heredity 72: 508-514.

IWANAGA K., NAKASUII F. \& ToIo S. 1987: Wing polymorphism in Japanese and foreign strains of the brown planthopper, Nilaparvata lugens. Entomol. Exp. Appl. 43: 3-10.

Land J. van't, van Putten P., ZwaAn B., Kamping A. \& van DELDEN W. 1999: Latitudinal variation in wild populations of Drosophila melanogaster: heritabilities and reaction norms. $J$. Evol. Biol. 12: 222-232.

MASAKI S. 1973: Climatic adaptation and photoperiodic response in the band-legged ground cricket. Evolution 26: $587-600$.

Mousseau T.A. \& RofF D.A. 1989: Geographic variability in the incidence and heritability of wing dimorphism in the striped ground cricket, Allonemobius fasciatus. Heredity $\mathbf{6 2}$ : 315-318.

Muraul M., Murua T. \& NaKasuri F. 1989: Phenological studies on the wing dimorphism of a semiaquatic bug, Microvelia douglasi (Heteroptera: Veliidae). Res. Popul. Ecol. 31: 129-138.

RoFF D.A. 1986: The evolution of wing dimorphism in insects. Evolution 40: 1009-1020.

SaKashita T., Fujisaki K. \& NaKasujI F. 1995: Environmental factors affecting wing length variation of a stink bug, Pyrrhocoris sibiricus (Heteroptera: Pyrrhocoridae). Appl. Entomol. Zool. 30: 303-308.

Shimizu T. \& MAsaki S. 1993: Genetic variability of the wingform response to photoperiod in a subtropical population of the ground cricket, Dianemobius fascipes. Zool. Sci. 10: 935-944.

SocHA R. 1993: Pyrrhocoris apterus (Heteroptera) - an experimental model species: a review. Eur. J. Entomol. 1: 241-286.

Tauber M.J., Tauber C.A. \& Masaki S. 1986: Seasonal Adaptations of Insects. Oxford University Press, New York, $411 \mathrm{pp}$.

VEPSÄLÄINEN K. 1971: The role of gradually changing daylength in determination of wing length, alary dimorphism and diapause in a Gerris odontogaster (Zett.) population (Gerridae, Heteroptera) in South Finland. Ann. Acad. Sci. Fenn. A IV, 183: $1-25$.

VEPSÄLÄINEN K. 1978: Wing dimorphism and diapause in Gerris: determination and adaptive significance. In Dingle H. (ed.): Evolution of Insect Migration and Diapause. Springer-Verlag, New York, pp. 218-253.

ZaR J.H. 1996: Biostatistical Analysis, 3rd edn. Prentice-Hall International, Inc., Simon \& Schuster/A Viacom Comp., New Jersey, 662 pp.

Received April 28, 2000; accepted October 3, 2000 